\title{
TIME-SPENT ONLINE AS A FACTOR IN USAGE AND AWARENESS OF DRAWBACKS IN SOCIAL MEDIA
}

\author{
Joanna Paliszkiewicz, Warsaw University of Life Sciences-SGGW,joanna_paliszkiewicz@sggw.pl \\ Magdalena Mądra - Sawicka, Warsaw University of Life Sciences-SGGW, magdalena_madra@sggw.pl \\ Tadeusz, Filipiak, Warsaw University of Life Sciences -SGGW, tadeusz_filipiak@sggw.pl \\ Salome Svanadze, Ilia State University, salome.svanadze.1@iliauni.edu.ge \\ Mariam Jikia, Georgian Technical University, marijiqia@gmail.com
}

\begin{abstract}
Social media become very important part of the life of many people. This paper reports on the state of time spent online and usage of social media by students. The purpose of this study was to investigate 1) the average assessment of the social media usage, 2) the frequency of the social media usage, and 3) the average rank for all drawbacks of social media usage based on users' time-spent on social media. A survey was administered to 197 students from Warsaw University of Life Sciences - SGGW, Faculty of Economic Sciences in April 2017. Collected data were analyzed among three groups of respondents divided according to time that they spend on the Internet each day. Descriptive statistics and non-parametric method of the Kruskal-Wallis test for testing the variance used for comparing three groups. Based on these results, respondents that spent more than 4 hours per day on the Internet have a better understanding of the purposes and drawbacks of social media use. Conclusions and recommendations were made based on the results.
\end{abstract}

Keywords: social media, purposes of using social media, drawbacks of social media

\section{INTRODUCTION}

Nowadays, the social media cites have become a part of social, professional, and business settings (Koohang, 2017). Social media technologies enable to connect people, share interests and activities across borders. It allows users to create a public or semi-public profile with user generated content and creates a network of people, with whom they would like to share information, videos, and photos (Paliszkiewicz, Koohang, 2016).

Social media is being adopted by millions of users, most of them are students, who spent a lot of time online. Many researchers confirmed that students primarily use social media sites for personal usage like socializing and entertainment, research also indicates that students are increasingly using social media as an opportunity to gain knowledge about educational matters (Dabbagh \& Kitsantas, 2012; Kim, 2017) and to get news from the world (Tandoc \& Johnson, 2016). This development has brought many changes in educational approach, especially in various pedagogical processes. The social media can support new ways of learning (Paliszkiewicz, Koohang, 2016). Some researchers (Valenzuela, et al., 2009) confirmed that social trust and life's satisfaction were related to the intensity of social media use (especially Facebook).

The purpose of this study was to investigate 1) the average assessment of the social media usage, 2) the frequency of the social media usage, and 3) the average rank for all drawbacks of social media usage based on users' time-spent on social media. In the first part of the article, a literature review was presented in the second part the result of the research was described. Findings and recommendations for further research are discussed at the end.

\section{Students and social media - literature review}

The terms social media refers to "web-based applications for communication and sharing information over the Internet" (Paliszkiewicz \& Koohang, 2016, p. 3). According to Safko and Brake (2009), social media are related to activities, practices, and behaviors among communities of people who gather online to share information, knowledge, 
and opinions using conversational media. Weinberg $(2009$, p.1) notes that social media "relates to the sharing of information, experiences, and perspectives throughout community-oriented websites". Social media takes on many different forms, including (Paliszkiewicz \& Koohang, 2016): social network sites (e.g., Facebook, LinkedIn), media sharing platforms (e.g., YouTube, Instagram, Pinterest), blogs (e.g. Blogger, WordPress), micro-blogs (e.g. Twitter), wikis (e.g., Wikipedia), virtual worlds (i.e. Second Life, World of Warcraft), location based services (e.g. Facebook Places, Foursquare), social bookmarking services (e.g., Delicious), group buying (e.g.Groupon, Living Social), writing communities' platforms (e.g. Wattpad, WritersCafe.org), review sites (e.g. TripAdvisor), Internet forums.

The main purposes of using social media are time passing (Papacharissi \& Rubin, 2000; Whiting \& Williams, 2013), communication with friends (Thackeray, et al., 2012; Shihab, 2015), communication with family members (PadillaWalker, et al., 2012), sending and receiving assignments from university (Subramani, 2015), finding social contacts (Leist, 2013), online learning (Cochrane \& Antonczak, 2014; Dron \& Anderson, 2014; Salmon, et al., 2015), leisure and entertainment (Whiting \& Williams, 2013), sharing information (Hashim, et al., 2016), personal promotion (Paliszkiewicz \& Mądra-Sawicka, 2016), share opinions (Wiid, et al., 2014).

The using of social media has also many drawbacks. Social media can damage one's reputation because of lack of privacy. Users share a lot of personal information on social websites such as favorite places, study place, interests, photos, etc. (Fatima, et al., 2015). This may lead to the creation of the opportunities for the unauthorized usage of user information and for example, there is a risk of fraud when using social media e.g., identity theft. Use of social media consumes both time and effort (Mohorjy, et al., 2015) and detaches users from direct contact with others. There is a risk of negative comments in social media (Walaski, 2013). Social media can have a negative influence on student productivity (Mohorjy, et al., 2015). For some people using social media is stressful and some people thinking that there are too many social media and it's difficult to learn them. Use of the social media is detrimental to both mental \& physical health and it can cause addiction (Webb \& Wasilick, 2015; Dwyer \& Fraser, 2016; Kuss \& Griffiths, 2017). The addiction can be compared to those experienced by individuals addicted to drugs or alcohol, for example, mood modification, salience, withdraw, conflicts.

It is very important to teach students time management and self-control. Students need to know how to create a balance between entertainment and learning when using social media. Social media has the potential to improve student engagement and to be used as a knowledge sharing tools, that it why it is very important to make research related to using social media by students.

\section{PURPOSE OF THE STUDY}

The purpose of this study was to investigate 1) the average assessment of the social media usage, 2) the frequency of the social media usage, and 3) the average rank for all drawbacks of social media usage based on users' time-spent on social media.

\section{RESEARCH METHODOLOGY}

\section{Survey}

The instrument consists of the questions related to time spent, knowledge, types, purposes and drawbacks of using social media and it based on the previous study presented by Dlamini, Ncube, \& Muchemwa, (2015). The instrument items were as follows:

1. How much time do you spend on the Internet each day (less than 2 hours, 3-4 hours, more than 4 hours)

2. Please rate your knowledge of the social media (excellent, very good, good, fair, poor)

3. Tick the section that best states your social media usage ( $5=$ Usually, $4=$ Frequently, $3=$ Sometimes, $2=$ Rarely, $1=$ Never):

- Blogs;

- Video Sharing (e.g., YouTube);

- Social Networks (e.g., Facebook);

- Business Social Networks (e.g., LinkedIn); 
- $\quad$ Social News (e.g., Digg, Reddit);

- Bookmarking (e.g., Delicious);

- Microblogs (e.g., Twitter);

- Photo Sharing (e.g., Flicker, Instagram, Pinterest);

- $\quad$ Social Measuring (e.g., Technorati, BlogPulse);

- Social Q\&A (e.g., Answers.com);

- Wikis (e.g., Wikipedia);

- Collaboration (e.g. Google Docs);

- Audio (e.g. Podcasts);

- Discussion Forums;

- Product Reviews (i.e. eopinions.com, TripAdvisor);

- Audio and Music Sharing (i.e. Last.fm);

- Virtual Worlds (i.e. SecondLife).

4. The purpose of Using the Social Media. Tick the section that best states your frequency of social media usage $(5=$ Usually, $4=$ Frequently, $3=$ Sometimes, $2=$ Rarely, $1=$ Never $)$ :

- Time passing;

- Communication with friends;

- Communication with family members;

- Sending and receiving assignments from University;

- Finding social contacts;

- Online learning;

- Leisure and entertainment;

- Sharing information;

- Personal promotion;

- Share opinions.

5. Drawbacks of using the social media. For the statements below tick the section that best states your

opinion. $5=$ Strongly Agree, $4=$ Agree, $3=$ Neutral, $2=$ Disagree, $1=$ Strongly Disagree.

- There are too many Social Medias and it's difficult to learn them.

- Using the social media is stressful.

- Social media damages one's reputation because of lack of privacy

- Use of the social media is detrimental to both mental \& physical health

- Use of social media consumes both time and effort.

- Social media can have a negative influence on student productivity.

- Use of social media detaches me from direct contact with others.

- There is a risk of negative comments in social media.

- There is risk of fraud when using social media e.g., identity theft

\section{Subjects and Procedure}

The subjects for this study were selected from students that studied in April of 2017 on Economic Sciences Faculty at Warsaw University of Life Sciences in Poland. Subjects were males and females who use social media on a daily basis and had constant access to the Internet. The questionnaire was translated from English to Polish language and administered to 197 students during lectures. It was the sample of convenience. The $49 \%$ of respondents' study economy, $28 \%$ management, $11 \%$ logistics, $6 \%$ finance and accounting and $6 \%$ commodities. The average age of the respondents was 22 . A total of 132 women and 65 men responded to the survey.

Almost, the majority - 50 percent - of respondents stated to use the internet per day longer than 4 hours, 51 percent 3 4 hours, while 19 percent less than 2 hours (Figure 1). 


\section{Issues in Information Systems}

Volume 18, Issue 4, pp. 135-145, 2017

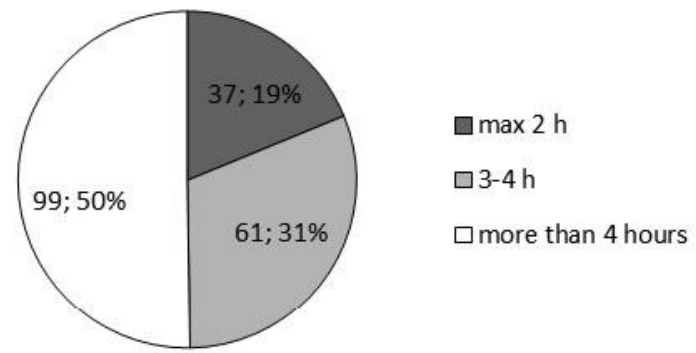

Figure 1. The division for a research group according to time spend on the Internet each day

The gender structure among responders was quite similar in three single out groups. The share of male responders was similar and amounted from $31 \%$ to $35 \%$ (Figure 2).

$\max 2 \mathrm{~h}$

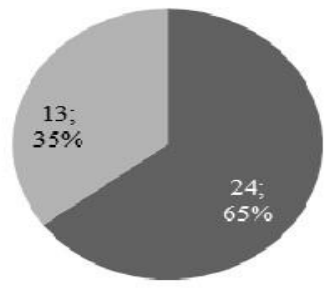

nemale Male
$3-4 h$

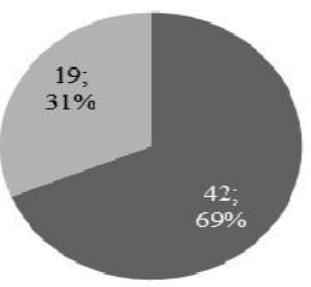

- Female Male more than $4 \mathrm{~h}$

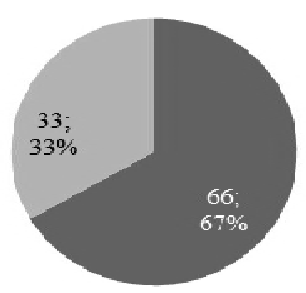

- Female Male

Figure 2. Gender structure according to time spend on the Internet each day

The responders assess the knowledge about social media (Figure 3). The highest number of answers concerned a good or a very good knowledge about social media. The highest share of this answers noticed in a group of responders that use the Internet per day longer than 4 hours (respectively $46.9 \%$ and 54.8\%). Also the highest share of answers "excellent" concern this groups of responders $-70.6 \%$ of indications.

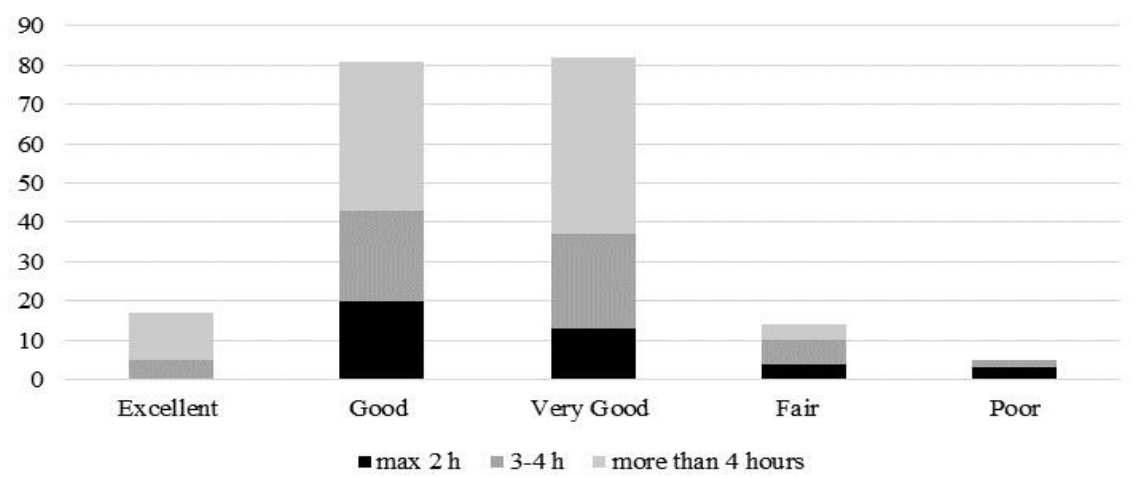

Figure 3. Knowledge of the social media 


\section{Analysis}

Analyses were conducted among three groups of respondents divided according to time that they spend on the Internet each day. Descriptive statistics were performed and non-parametric method of the Kruskal-Wallis test was used to find out 1) the average assessment of the social media usage, 2) the frequency of the social media usage, and 3) the average rank for all drawbacks of social media usage based on users' time-spent on social media.

\section{RESULTS}

Figure 4 presents the most usually used social media platform. Responders matched the social network ( 873 all ranks $-4,43$ average rank) as a most usually used type of social media. Responders that use the Internet longer than 4 hours were responsible for $52.7 \%$ of all rank points. This tendency of the high rank in the last group constituted over $50 \%$ of share and repeat in almost all distinguish social media type in a research survey. The second most highly ranked answers concerned using Wikis (777 ranks - average rank 3.94), the third Video Sharing (667 ranks - average rank 3.38). In fourth place due to the frequency of use, the students pointed to Google doc as a platform to improve collaboration (512 ranks - average rank 2,60).

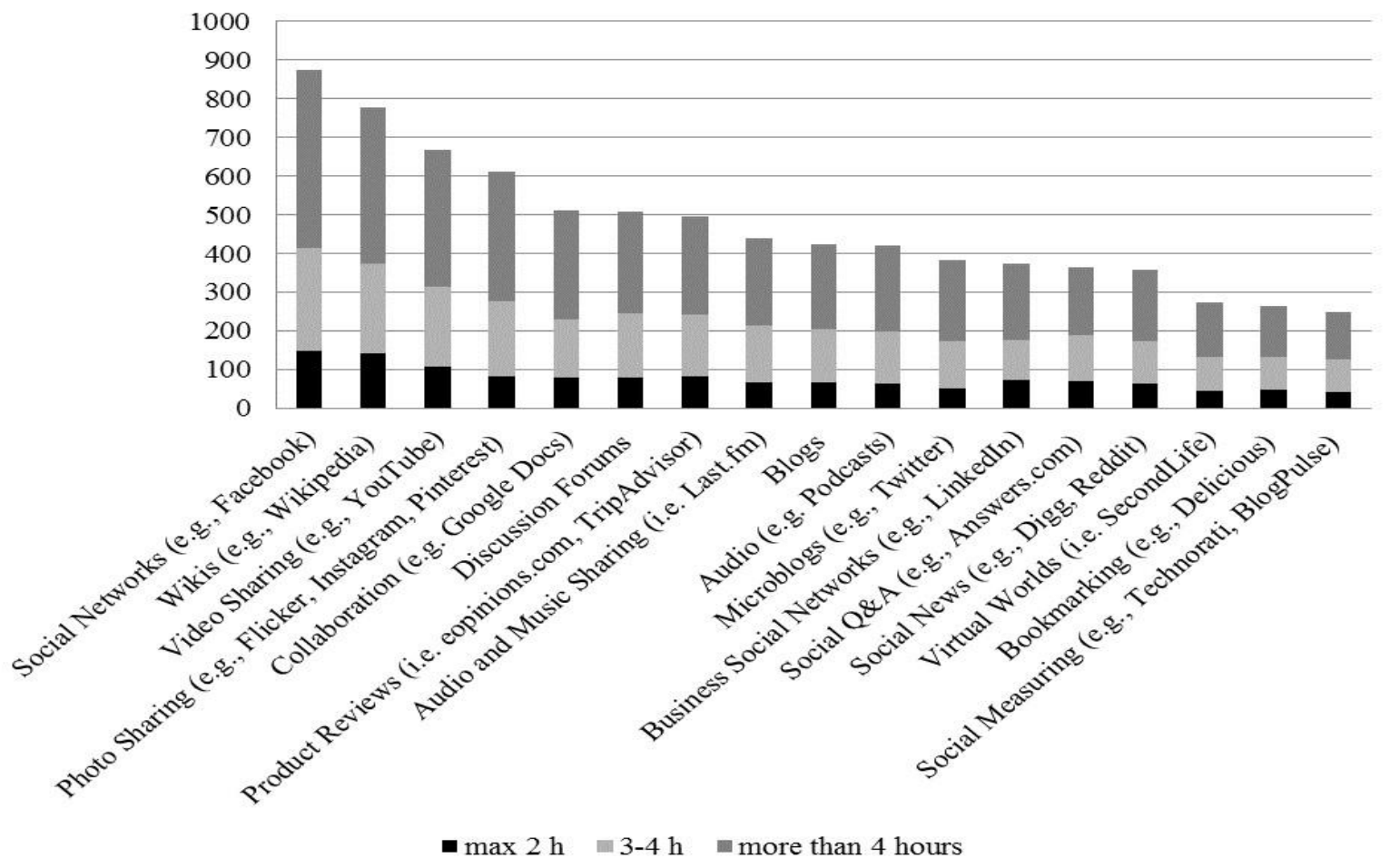

Figure 4. Type of social media usage (1 - never, 5 - usually)

Figure 5 presents the average assessment of the social media usage. The median level of social media usage was the lowest in a group that uses the Internet no longer than 2 hours per day, while in the rest both groups this level was quite similar.

Table 1 reveals the results of the Kruskal-Wallis test variance analysis according to the statistical significance between the three groups indicating 'time spend on the Internet each day' as a factor with significantly different responders concerning the most often use social media platform. There was a significant difference (p-value lower than 0.05) between averaged rank of usually used social media platform among responders that use the Internet no longer that 2 hours per day and the group that uses the Internet 3-4 hours and more than 4 hours. There was no significant difference between the group that uses the Internet between 3-4 and over 4 hours concerning the most often used platform of social media. 


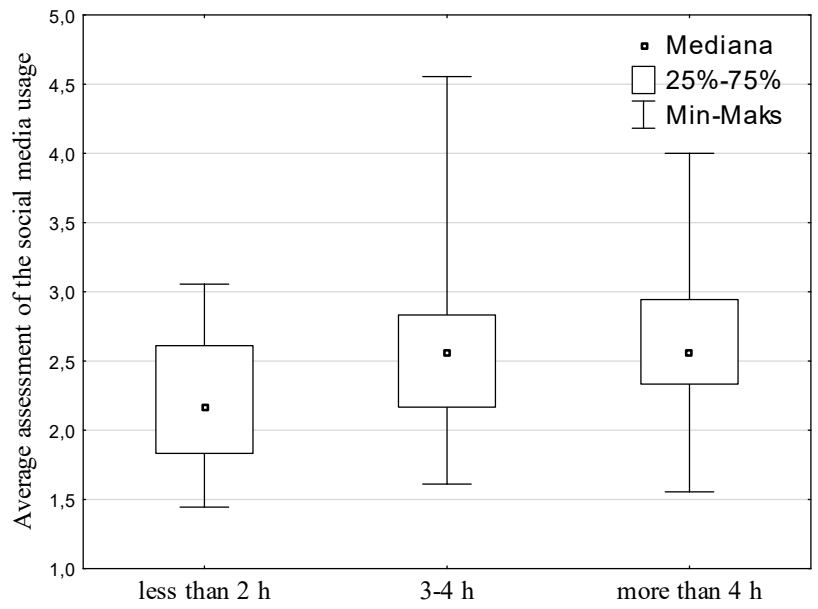

Table 1. Kruskal-Wallis test for the average assessment of the social media usage

\begin{tabular}{|l|c|c|c|}
\hline \multicolumn{4}{|c|}{$\mathrm{H}(2, \mathrm{~N}=197)=16.55790, \mathrm{p}=0.0003$} \\
\hline & $\begin{array}{c}\text { Less than } \\
\mathbf{2 ~ h}\end{array}$ & $\mathbf{3 - 4} \mathbf{~ h}$ & $\begin{array}{c}\text { More } \\
\text { than 4h }\end{array}$ \\
\hline $\begin{array}{l}\text { Less than } \\
\text { h }\end{array}$ & & $2.918136^{*}$ & $4.057520^{*}$ \\
\hline $3-4 \mathrm{~h}$ & $2.918136^{*}$ & & 1.067511 \\
\hline $\begin{array}{l}\text { More than } \\
\text { 4h }\end{array}$ & $4.057520^{*}$ & 1.067511 & \\
\hline
\end{tabular}

$* \mathrm{p}<0.05$

Figure 5. Box plots. Average assessment of the social media usage (1 - never, 5 - usually)

The figure 6. reveals responses regarding the frequency of social media usage according to rank points (sum of rank points in each group). The most often indicated purpose of social media usage was communication with friends - that noticed 4.56 of average rank ( 900 total ranks). Social media was also very frequently used by responders in sending and receiving assignments from University - average rank 4.14. The third most often indicated purpose was online learning (3.82 average ranks). All answers of responders that use the Internet for the longest time than 4 hours constituted around $50 \%$ of ranks point for each frequency use of social media platform. Almost not used the function of a social media in research group was a personal promotion. This feature could more important when people are older.

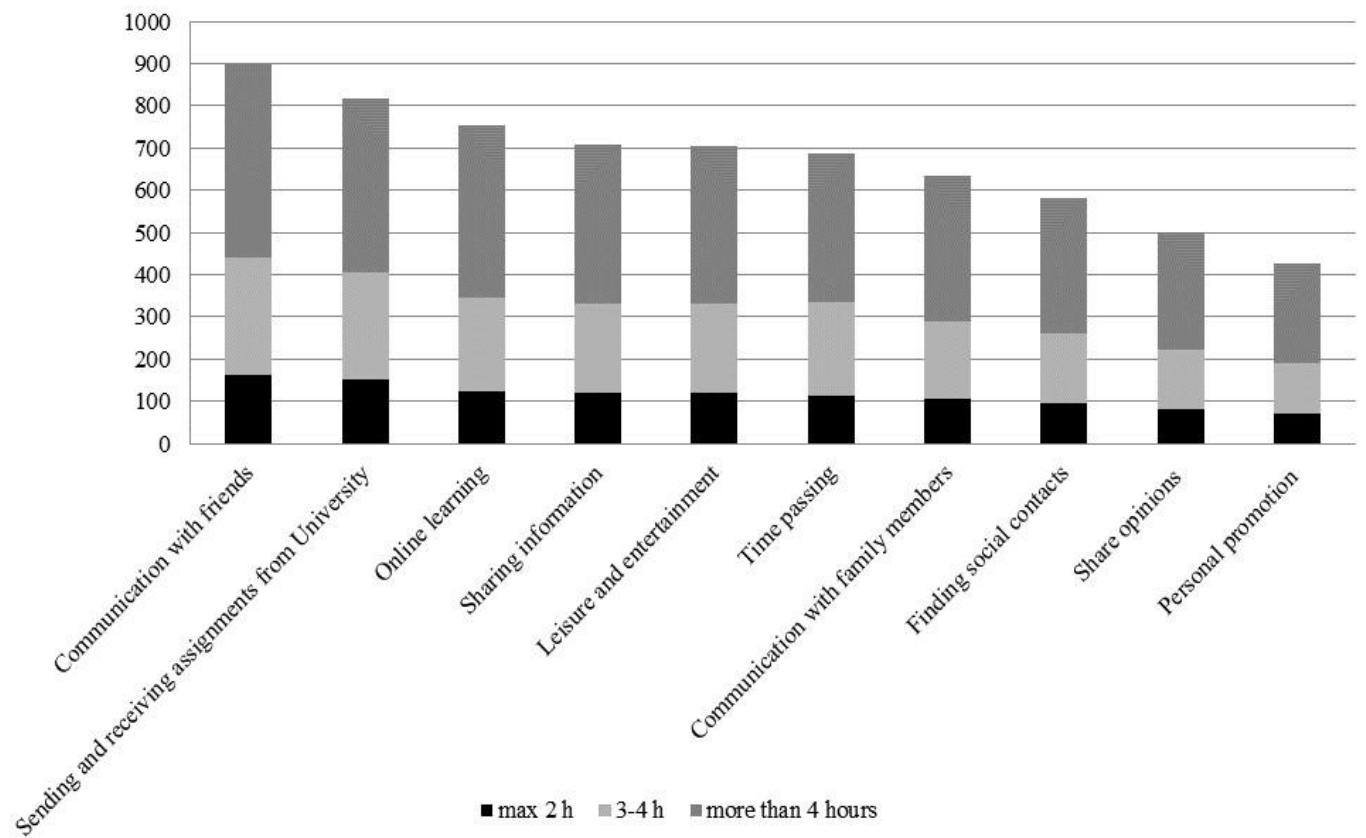

Figure 6. Frequency of social media usage in relation to purposes (1 - never, 5 - usually)

Figure 7 presents the average assessment of the frequency social media usage in relation to purposes. The median level of social media usage was the lowest in a group that uses the Internet no longer than 2 hours per day and the 


\section{Issues in Information Systems}

Volume 18, Issue 4, pp. 135-145, 2017

highest in a group that uses the Internet longer than 4 hours. The main purposes of using social media were: communication with friends, sending and receiving assignments from University and online learning. The less important purpose was using social media for personal promotion.

Table 2 reveals the result of the Kruskal-Wallis test concerning frequency of the social media usage. The significant difference (p-value lower than 0.05) occurred between averaged ranks among responders that use the Internet no longer that 2 hours per day and the group that uses the Internet more than 4 hours as well as between 3-4 hours and over 4 hours. There was no significant difference between the group that uses the Internet between 3-4 and less than 2 hours.

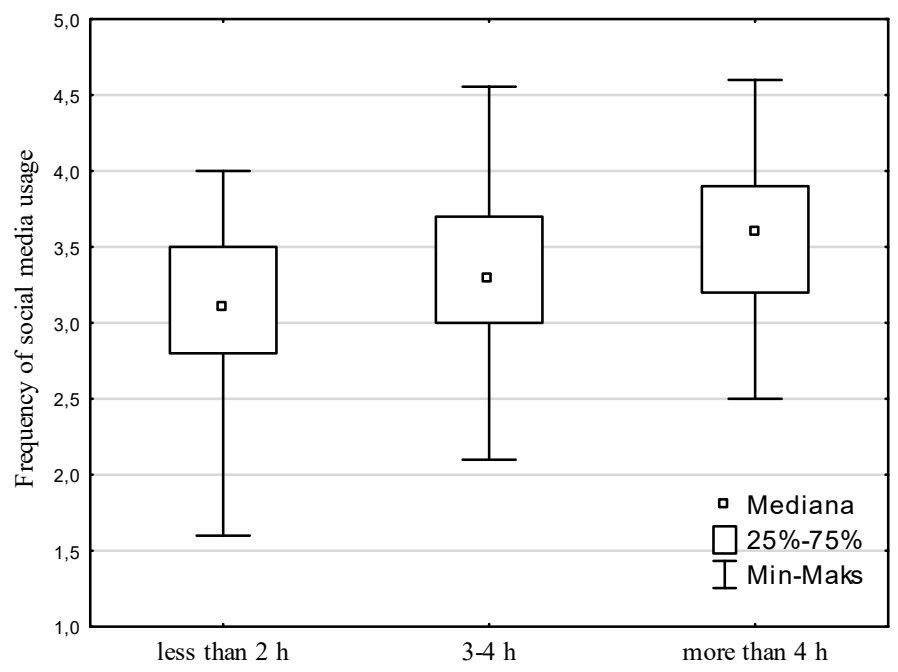

Table 2. Kruskal-Wallis test for the frequency of social media usage

\begin{tabular}{|l|c|c|c|}
\hline \multicolumn{4}{|c|}{$\mathrm{H}(2, \mathrm{~N}=197)=21.62132, \mathrm{p}=0.0000$} \\
\hline & $\begin{array}{c}\text { Less than } \\
\mathbf{2 ~ h}\end{array}$ & $\mathbf{3 - 4} \mathbf{~ h}$ & $\begin{array}{c}\text { More } \\
\text { than 4h }\end{array}$ \\
\hline $\begin{array}{l}\text { Less } \\
\text { than 2 } \\
\text { h }\end{array}$ & & 1.653643 & $4.319967^{*}$ \\
\hline 3-4 h & 1.653643 & & $2.996966^{*}$ \\
\hline $\begin{array}{l}\text { More } \\
\text { than 4h }\end{array}$ & $4.319967^{*}$ & $2.996966^{*}$ & \\
\hline
\end{tabular}

Figure 7. Box plots. Frequency of the social media usage (1 - never, 5 - usually)

Respondents were asked about their experience with social media drawbacks (Figure 8). The most often indicated answer by responders was „the risk of negative comments on social media” (4.72 average rank - also the highest rank of this answers belong to the group that uses the Internet for a long time that 4 hours per day). The second often mentioned assessment was a statement that assessed social media as a high source of the risk of fraud (identity theft) - 4.31 average rank. The third-ranked statement concerned social media was a time and effort consuming disadvantage, with almost $50 \%$ of points ranks in a group that uses the Internet longer than 4 hours. The answer that was not assessed as drawbacks was a statement that "using social media is stressful" (1.25 average rank). 


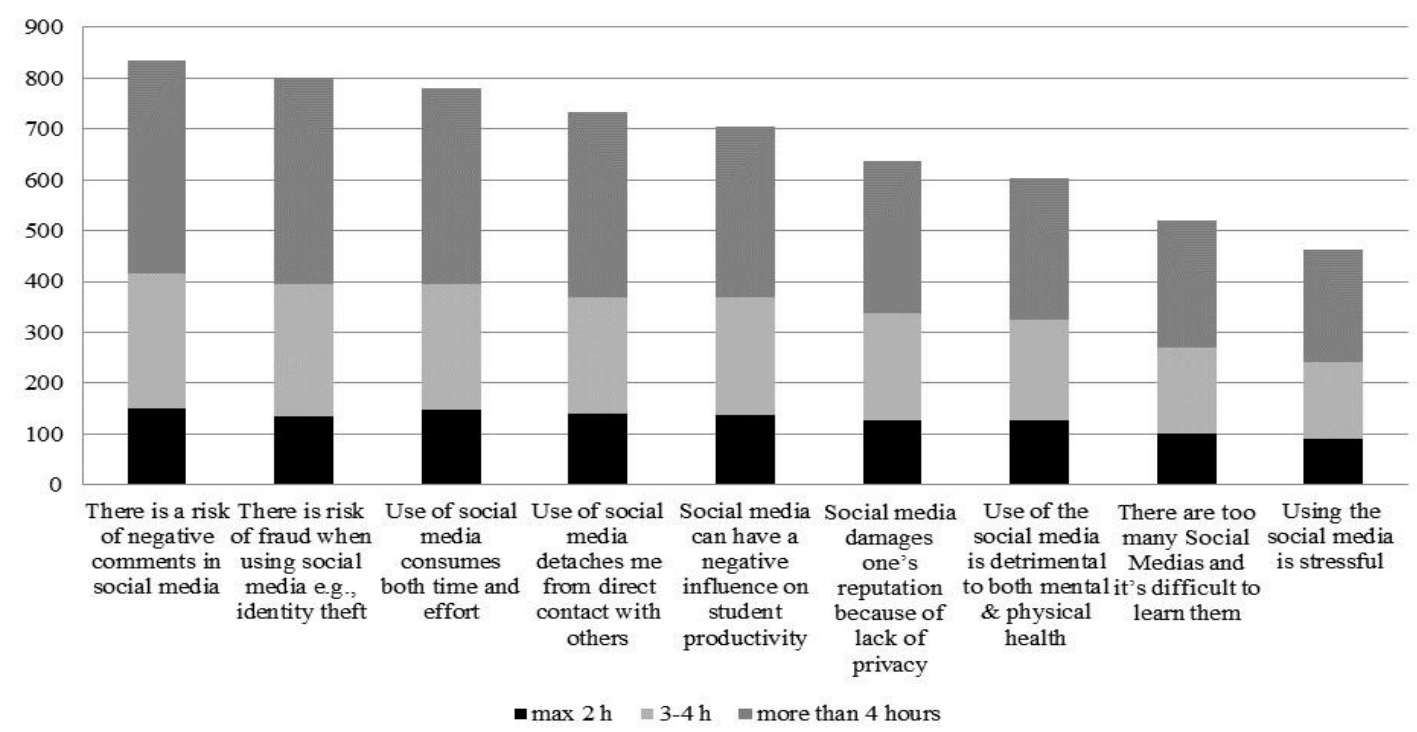

Figure 8. Drawbacks of social media usage (1 - strongly disagree, 5 - strongly agree)

Figure 9 presents the average assessment of the drawbacks of social media usage. The median level of the drawbacks was the lowest in a group that uses the Internet longer than 4 hours. The greatest variability of responses occurred among these Internet users who were online 3-4 hours per day.

Table 3 reveals the result of the Kruskal-Wallis test concerning drawbacks of the social media usage. The significant difference ( $\mathrm{p}$-value lower than 0.05 ) occurred only between averaged ranks among responders that use the Internet no longer that 2 hours per day and the group that uses Internet 3- 4 hours per day and over 4 hours.

Results by platform, purposes, and drawbacks are presented in this paper which distinctly places of a time spent on the Internet each day. Based on these results, responders that spent more than 4 hours per day on the Internet have a better understanding of the purposes, drawbacks of social media use. Responders that spent such much time on the Internet every day assessed social media as a time and effort consuming as a third in order drawbacks.

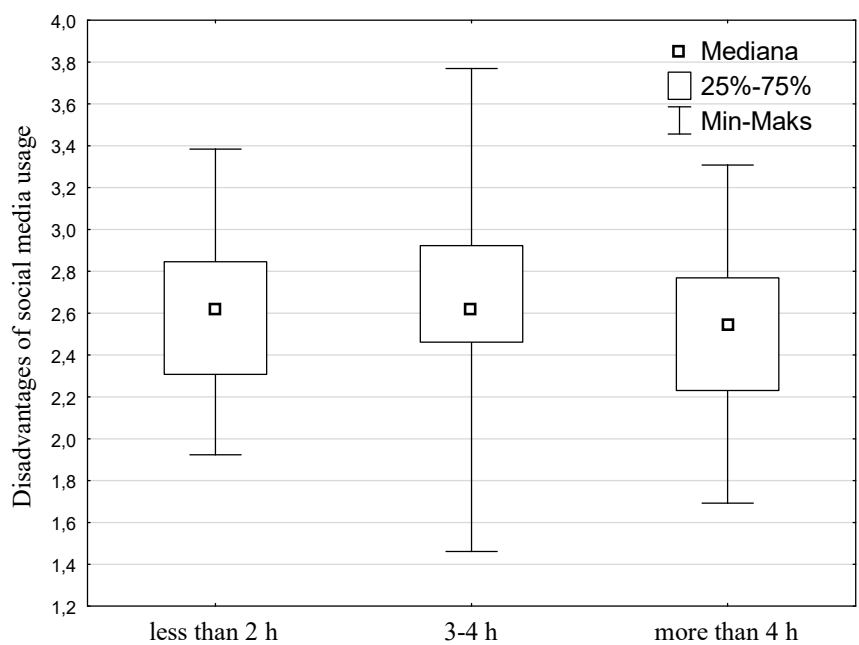

Figure 9. Box plots. The average rank for all drawbacks of social media usage (1 - strongly disagree, 5 - strongly agree)
Table 3. Kruskal-Wallis test for the drawbacks of social media usage

\begin{tabular}{|l|c|c|c|}
\hline \multicolumn{4}{|c|}{$\mathrm{H}(2, \mathrm{~N}=197)=9.588118 \mathrm{p}=0.0083$} \\
\hline & $\begin{array}{c}\text { Less than } \\
\mathbf{2 ~ h}\end{array}$ & $\mathbf{3 - 4} \mathbf{~ h}$ & $\begin{array}{c}\text { More } \\
\text { than 4h }\end{array}$ \\
\hline $\begin{array}{l}\text { Less than } \\
\text { 2 h }\end{array}$ & & 0.832528 & 1.639109 \\
\hline $3-4 \mathrm{~h}$ & 0.832528 & & $3.006138^{*}$ \\
\hline $\begin{array}{l}\text { More than } \\
\text { 4h }\end{array}$ & 1.639109 & $3.006138^{*}$ & \\
\hline
\end{tabular}

$* \mathrm{p}<0.05$ 


\title{
Issues in Information Systems
}

Volume 18, Issue 4, pp. 135-145, 2017

\begin{abstract}
SUMMARY
The usage of social media is increasing and the potential to use it in education is higher. Nowadays, students are experienced in the digital world from an increasingly early age, adopting new technologies very quickly. They live on social networks, creating relationships, sharing information. Today, students can simultaneously do homework, listen to music and for example send messages. As social media are developing, universities should consider effectively integrating them as a supportive took to enhance active learning.

In every social media platform, the group of responders that spent more than 4 hours per day on the Internet ranked higher the frequency of their usage and fear of negative comments. Drawbacks connected with time spent on social media was assessed as important relation mostly in a group that spends on the Internet less than 2 hours per day, while in the group that this time exceeds $4 \mathrm{~h}$ responders did not confirm this as important.
\end{abstract}

According to the literature, students use social media for the purpose of sending and receiving assignments in online learning, but they are not aware of the possibility to use it for personal promotion. Impression management in social media is becoming very important (Paliszkiewicz \& Mądra-Sawicka, 2016). It is a process in which people attempt to influence the perceptions of their image, they do it by controlling and managing information presented in social media (Drory \& Zaidman, 2007). It is a key to success or failure in business life (Rui, Stafanone 2013). The topic of selfpresentation and personal promotion was examined by DeAndrea \& Walther (2011), Labrecque, et al., (2011), Schwämmlein \& Wodzicki (2012), Birnbaum (2013). People engage in self- presentation and personal promotion for many social and professional reasons, including to gain employment (Dekay 2009; Bohnert \& Ross, 2010; Madera, 2012), to conduct business, to establish friendships, to express themselves (Shepherd, 2005; Bolino et al., 2008) or to correct inaccurate impressions that colleagues have of them (Giacalone \& Rosenfeld, 1991). The lack of awareness of using social media for personal promotion should be changed. Education is needed in this area. People should be active in the personal promotion and should know what information exists about them in social media and if the information is protected by the appropriate levels of security and privacy. According to research people are conscious about the risk of fraud e.g. identity theft but the level of awareness of privacy issue is lower. Also, the education in this area is needed.

Limitations of the study include the number of respondents, their age, and the limited geographic area. Results from additional countries would enrich the study and make it more generalizable to a global population.

In the future research, it will be good to find out how and for which purposes social media can be effectively used in an educational context to support and enhance learning. It will be worth to make research how people enhance to share knowledge, resources with one another. Also, the important area is related to people addicted to social media. More study is needed to understand this problem and to create protection to young people. Another study can research the problem of the time management and the performance of the people. Is it possible that people who spend more than four hours per day in social media were effective at school or at work? Will it influence on their future career? It is also important to focus research on the network created in social media. Does the trust online appear among the people? How to develop this kind of trust? How to rebuild it, if it is destroyed? Do the networks help people to develop and build future careers?

\section{REFERENCES}

Birnbaum, M. G. (2013). The fronts students use: Facebook and the standardization of self-presentations. Journal of College Student Development, 54(2), 155-171.

Bohnert, D., \& Ross, W. H. (2010). The influence of social networking web sites on the evaluation of job candidates. Cyberpsychology, Behavior and Social Networking, 13(3), 341-347.

Bolino, M. C., Kacmar, K. M., Turnley, W. H., \& Gilstrap, J. B. (2008). A multilevel review of impression management motives and behaviors. Journal of Management, 34, 1080-1109.

Cochrane, T., \& Antonczak, L. (2014). Implementing a mobile social media framework for designing creative pedagogies. Social Sciences, 3(3), 359-377. 
Dabbagh, N., \& Kitasantas, A. (2012). Personal Learning Environments, social media, and self-regulated learning: A natural formula for connecting formal and informal learning. The Internet and Higher Education, 15, 38.

DeAndrea, D. C., \& Walther, J. B. (2011). Attributions for inconsistencies between online and offline selfpresentations. Communication Research, 38(6), 805-825.

Dekay, S. (2009). Are business-oriented social networking web sites useful resources for locating passive jobseekers? Results of a recent study. Business Communication Quarterly, 72(1), 101-105.

Dlamini, C., Ncube, F., \& Muchemwa, S. (2015). The use of social media technology in universities: A case of Solusi University, Zimbabwe. Journal of Media and Communication Studies, 7(5), 101-111.

Dron, J., \& Anderson, T. (2014). On the design of social media for learning. Social Sciences, 3(3), 378-393.

Drory, A., \& Zaidman N. (2007). Impression management behavior: effects of the organizational system. Journal of Managerial Psychology, 22, 290-308.

Dwyer, R., \& Fraser, S. (2016). Addicting via hashtags: How is twitter making addiction? Contemporary Drug Problems, 43(1), 79-97.

Fatima, S., Manzoor, U., Zafar, B., \& Balubaid, M. A. (2015). Analyzing the impact of social media on users. International Journal of Computer Science Issues (IJCSI), 12(3), 141-145.

Giacalone, R. A., \& Rosenfeld, P. (1991). Applied impression management: How image making affects managerial decisions. Newbury Park, CA: Sage.

Hashim, K., Al-Sharqi, L., \& Kutbi, I. (2016). Perceptions of social media impact on social behavior of students: A comparison between arts and science faculty. Online Journal of Communication and Media Technologies, 6(4), 147-165.

Kim, C. (2017). Out-of-class communication and personal learning environments via social media: Students' perceptions and implications for faculty social media use. Teaching Journalism \& Mass Communication, 7(1), 62-76.

Koohang, A. (2017). Social media sites privacy concerns: Empirical validation of an instrument. Online Journal of Applied Knowledge Management, 5(1), 14-26.

Kuss, D. J., \& Griffiths, M. D. (2017). Social networking sites and addiction: Ten lessons learned. International Journal of Environmental Research and Public Health, 14(3), 311.

Labrecque, L. I., Markos, E., \& Milne, G. R. (2011). Online personal branding: Processes, challenges, and implications. Journal of Interactive Marketing, 25(1), 37-50.

Leist, A. K. (2013). Social media use of older adults: A mini-review. Gerontology, 59(4), 378-384.

Madera, J. M. (2012). Using social networking websites as a selection tool: The role of selection process fairness and job pursuit intentions. International Journal of Hospitality Management, 31(4), 1276-1282.

Mohorjy, A., Al-Sharqi, L., Hashim, K., \& Kutbi, I. (2015). Gender differences on perceptions of social media as a learning tool. West East Journal of Social Sciences, 4(1), 10-21.

Padilla-Walker, L., Coyne, S. M., \& Fraser, A. M. (2012). Getting a high-speed family connection: Associations between family media use and family connection. Family Relations, 61(3), 426-440. 
Paliszkiewicz, J., \& Koohang, A. (2016). Social Media and Trust: a Multinational Study of University Students, Informing Science Press, California.

Paliszkiewicz, J., \& Mądra-Sawicka, M. (2016). Impression management in social media: the example of LinkedIn. Management, 11(3), 115-124.

Papacharissi, Z. \& Rubin, A. M. (2000). Predictors of internet use. Journal of Broadcasting \& Electronic Media, 44(2), 175-196.

Rui, J. R., \& Stefanone, M. A. (2013). Strategic self-presentation online: A cross cultural study. Computers in Human Behavior, 29(1), 110-118.

Safko, L., \& Brake, D. K. (2009). The social media bible: Tactics, tools \& strategies for business success. Hoboken, NJ: John Wiley \& Sons.

Salmon, G., Ross, B., Pechenkina, E., \& Chase, A. (2015). The space for social media in structured online learning. Research in Learning Technology, 23, 1-14.

Shepherd, I. D. H. (2005). From cattle and Coke to Charlie: Meeting the challenge of self marketing and personal branding. Journal of Marketing Management, 21(5), 589-606.

Shihab, I. (2015). Social media awareness and use among LIS professionals in India: A study. International Journal of Information Dissemination and Technology, 5(2), 68-74.

Schwämmlein, E., \& Wodzicki, K. (2012). What to tell about me? Self-presentation in online communities. Journal of Computer-Mediated Communication, 17(4), 387-407.

Subramani, R. (2015). The academic usage of social networking sites by the university students of Tamil Nadu. Online Journal of Communication and Media Technologies, 5(3), 162-175.

Tandoc, E. C. Jr, \& Johnson, E. (2016). Most students get breaking news first from twitter. Newspaper Research Journal, 37(2), 153-166.

Thackeray, R., Neiger, B. L., Smith, A. K., \& Van Wagenen, S. B. (2012). Adoption and use of social media among public health departments. BMC Public Health, 12, 242.

Valenzuela, S., Park, N. \& Kee, K. F. (2009). Is there social capital in a social network site?: Facebook use and college students' life satisfaction, trust, and participation. Journal of Computer-Mediated Communication, 14 , 875-901.

Walaski, P. (2013). Social media. Professional Safety, 58(4), 40-49.

Webb, M. C., \& Wasilick, L. M. (2015). Addressing social media addiction via the classroom. Journal of Health Education Teaching Techniques, 2(3), 1-9. Media, Inc.

Weinberg, T. (2009). The new community rules: Marketing on the social web Sebastopol, CA: O'Reilly

Whiting, A., \& Williams, D. (2013). Why people use social media: A uses and gratifications approach. Qualitative Market Research, 16(4), 362-369.

Wiid, J. A., Cant, M. C., \& Nell, C. E. (2014). Perceptions and uses of social media networking systems by South African students. The International Business \& Economics Research Journal (Online), 13(4), 715-725. 